\title{
Diagnostic methods in viral hepatitis
}

Edited by P. S. Gardner and C. R. Howard. 1979. Laboratory and Research Methods in Biology and Medicine Series, volume 2. New York: Alan R. Liss, Inc. Pp. xi and 92. US $\$ 12.00$. (Available in Europe only from European Book Service, Flevolaan 36-38, PO Box 124, 1380 AC Weesp, Holland, Dutch Guilders 36.00).

This book is a bound version of one number of the Journal of Medical Virology (vol. 3, no. 1, 1978), and is the proceedings of a symposium held on January 7 th, 1978. It is concerned almost totally with hepatitis B. Hepatitis A is mentioned briefly in the opening review by Zuckerman, as is non-A, non-B hepatitis. The rest of the issue is taken up with fairly technical accounts of various aspects of testing for the antigenic components of the hepatitis $B$ virus and antibodies to them. It is inevitable that such a book, made up of 15 papers given at a one-day symposium, is somewhat fragmented and uneven. Nevertheless, taken individually they contain valuable accounts by those actually using the techniques, even though someone purchasing the book from a catalogue might imagine that he is buying a comprehensive account of the subject. This is not a criticism of the authors or of the organisers, but rather of the book as a publishing event. Presumably it could be bought for half the price in its original form. In its present format it is, in fact, a sheep in wolf's clothing.

\section{A. P. WATERSON}

\section{Phage-typing of coagulase-negative staphylococci}

Edited by G. Pulverer, P. B. Heczko and G. Peters. 1979. Stuttgart and New York: Gustav Fischer Verlag. Pp. vi and 167. DM 46.00.

This report of the 1st International Conference on phage-typing of coagulase-negative staphylococci, held in Cologne in 1977, provides basis data on the bacteriophages currently in use for typing these organisms, the experience of several centres in the application of phage-typing systems to epidemiological problems, and discussion of the need to improve the investigation of serious infections, particularly those affecting prosthetic heart valves. It will appeal not only to phage specialists but to anyone interested in coagulase-negative staphylococci and in implant surgery. The contributions include epidemiological and clinical findings as well as biotyping data. However, the methods of biotyping used by the various authors are not consistent.

The aim of the meeting was to consider the data available and to initiate studies into the feasibility of establishing an "international set" of phages, and the report ends with an "opening statement" setting up an informal working group.

The articles fall loosely into three groups. Firstly, papers from Professor Pulverer's institute describe the morphology and behaviour of the phages, in relation to the whole of the Micrococcaceae; phage absorption may be a useful taxonomic technique in this family. Secondly, papers from several laboratories describe the usefulness of their respective phage-sets for typing local strains of staphylococci, and there are some suggestions opposing the value of an international set. The technique of "reverse typing", i.e., determining the host-range of phages carried by field strains, is also described. Lastly, there are papers in which phage typing is described as a method of elucidating epidemiological and clinical problems.

The importance of coagulase-negative staphylococci, especially Staphylococcus epidermidis biotype 1 , in patients with prosthetic valve implants is reiterated in several articles. However, in serious infections biotyping tends to be of value only rarely. Antibiotic susceptibility of the staphylococci is dealt with by several groups of workers, and the frequency of resistance in clinical situations is emphasised. As several papers indicate, an individual can carry up to seven phage-distinguishable strains on his skin, which makes for difficulty in epidemiological investigations.

R. R. MARPLES

\section{Antimicrobial prophylaxis in surgery}

Edited by M. R. B. Keighley and D. W. Burdon. 1979. Tunbridge Wells, Kent: Pitman Medical. Pp. $x$ and 241. $£ 12.00$.

I have no doubt that this unique book should be essential reading for all microbiologists and 